\title{
Avaliação em Psicologia Positiva: Técnicas e Medidas
}

Hutz, C. S. (Org.) (2016). Avaliação em Psicologia Positiva: Técnicas e Medidas. São Paulo: CETEPP- Hogrefe.

Em 2014, o professor e pesquisador Cláudio Simon Hutz, da Universidade Federal do Rio Grande do Sul (UFRGS), organizou um livro pioneiro que apresentava instrumentos voltados para a avaliação de sete fenômenos de interesse da Psicologia Positiva (PP). Esse livro, Avaliação em Psicologia Positiva, além de apresentar diferentes instrumentos de avaliação e de oferecer tabelas com normas para auxiliar a interpretação dos escores obtidos, o que é de fundamental importância para aqueles que pretendem utilizar medidas da Psicologia Positiva em pesquisas e intervenções, mostra como o campo da Psicologia Positiva tem crescido nacionalmente. Uma resenha desse livro pode ser obtida em: http:/ / pepsic.bvsalud.org/pdf/avp/v14n1/ v14n1a19.pdf

Corroborando o cenário de avanço na produção de conhecimento e de instrumentos para a avaliação de fenômenos da Psicologia Positiva nacionalmente, mais especificamente na ocasião do segundo Congresso Brasileiro de Psicologia Positiva, ocorrido em 2016, o professor Cláudio Simon Hutz lança então um segundo livro, intitulado Avaliação em Psicologia Positiva: Técnicas e Medidas, o qual é foco desta resenha. Nesse livro, são apresentados nove novos fenômenos de interesse da Psicologia Positiva, em comparação ao livro mencionado anteriormente, além de instrumentos e normas para a interpretação dos escores gerados por essas medidas. Isso faz com que o livro seja uma ferramenta relevante aos psicólogos atuantes e pesquisadores.

O livro Avaliação em Psicologia Positiva: Técnicas e Medidas possui 182 páginas, divididas em nove capítulos breves e bastante informativos, com o intuito de discutir e apresentar instrumentos para a avaliação dos seguintes fenômenos: forças e virtudes, mindfulness, engajamento no trabalho, suporte social percebido, bem-estar subjetivo infantil, amizade, altruísmo, resiliência e autocompaixão. Esses capítulos serão apresentados na sequência.

No primeiro capítulo, denominado Forças e Virtudes: escala de forças de caráter, Ana Paula Porto Noronha e Altemir José Gonçalves Barbosa apresentam as seis forças de caráter, tal como propostas por Seligman e Peterson. Além disso, os autores apresentam estudos de construção e de busca de evidências de validade da Escala Brasileira de Forças e Virtudes, a partir do modelo teórico proposto no tão falado instrumento VIA Character Strenghts. Entretanto, os autores lembram que, apesar de a teoria original prever seis virtudes, quando analisada empiricamente, a dimensionalidade desse fenômeno, tanto na cultura brasileira quanto em outras culturas internacionais, não é corroborada. Dessa forma, no Brasil, ao invés das seis forças típicas, há apenas uma força geral. Outrossim, os autores apresentam normas para a correção e interpretação dos resultados da escala brasileira de forças caráter.

O segundo capítulo, escrito por Carolina Tozzi Reppold e Carolina Menezes, intitula-se Mindfulness. Nesse capítulo, as autoras apresentam a complexidade envolvida na tarefa de definição, operacionalização e mesmo utilização da atenção plena. Nesse texto, a definição de mindfulness se dá por meio de duas perspectivas diferentes, quais sejam: mindfulness como a) uma prática meditativa e b) como um construto psicológico. Apesar do cenário de complexidade na definição desse construto, uma variedade de intervenções e mesmo de instrumentos para avalia-la têm sido elaborados atualmente. Outrossim, nesse capítulo, as autoras apresentam oito instrumentos internacionais para avaliação da atenção plena e destacam quatro deles que possuem evidência de validade com amostras brasileiras.

Ana Claudia Souza Vazquez, Juliana Cerentini Pacico, Emília dos Santos Magnam, Cláudio Simon Hutz e Wilmar B. Schaufeli são autores do terceiro capítulo, denominado Avaliaşão do engajamento das pessoas com seu trabalho: a versão brasileira da escala Utrecht de engajamento no trabalho (UWES). Nesse texto, os autores abordam a importância do estar engajado com o trabalho, tanto para o resultado final da tarefa, quanto para a saúde das pessoas, de forma que, para analisar esse construto, faz-se necessário colocar as pessoas e seus vínculos de bem-estar e qualidade de vida no trabalho no centro do debate. Os autores apresentam a escala Utrecht de engajamento no trabalho, elaborada em 2004, acompanhada de sua versão adaptada à cultura brasileira (2015). Igualmente, são descritas normas para a interpretação dos escores gerados com esse instrumento.

O quarto capítulo, intitula-se Escala de suporte social percebido (ESSP) e foi escrito por Micheline Roat Bastianello e Claudio Simon Hutz. Os autores indicam que essa escala diz respeito a uma adaptação da 2-way SSS, 
desenvolvida em 2011 e que, além de avaliar o suporte em si, acrescenta o apoio recebido pelo indivíduo. Para os autores, uma das teorias mais aceitas para o suporte social reconhece quatro componentes, quais sejam: a) emocional, b) instrumental, c) informacional e 4) de avaliação. Nesse capítulo também são apresentadas as formas de aplicação e de correção dessa escala, além das normas para o levantamento e interpretação dos escores obtidos com ela.

$\mathrm{Na}$ sequência, Cláudia Hofheinz Giacomoni, Luciana Karine de Souza e Claudio Simon Hutz apresentam o capítulo quinto, chamado Indicadores de bem-estar subjetivo infantil: o que dizem as crianças. Nesse texto, os autores discutem a importância de se considerar e mesmo avaliar o bem-estar subjetivo na população infanto-juvenil. Com esse objetivo, os autores destacam um estudo para buscou conhecer indicadores de bem- estar em crianças brasileiras e, a esse respeito, todos os indicadores levantados pelas crianças no Brasil mostraram-se consonantes com os levantados por crianças da Finlândia, Inglaterra e Espanha. Esses indicadores podem permitir a elaboração de instrumentos e mesmo de intervenções no âmbito do bem-estar infantil.

No capítulo sexto, As escalas dos questionários McGill de amizade, Luciana Karina de Souza, Juliana Ávila-Souza e Gustavo Gauer apresentam os seguintes instrumentos: Escala de Funções da Amizade, o Questionário Introdutório de Amizade Reduzido (Souza, 2015), Escala de Satisfação com a Amizade e de Sentimentos Positivos com Relação ao Amigo e, ainda, a Escala de Sentimentos Negativos com Relação ao Amigo. Além de apresentar os instrumentos, os quais foram validados com amostras brasileiras por Souza e Hutz (2007), o capítulo oferece normas para o levantamento e a interpretação dos escores dessas escalas.

O sétimo capítulo foi escrito por Juliana Cerentini Pacico e Cláudio Simon Hutz, e denomina-se Altruísmo. Nesse capítulo, os autores fundamentam o construto altruísmo e apresentam um estudo de adaptação da Escala de altruísmo, composta por 20 itens que avaliam três fatores (ajuda ou auxílio, custo pessoal, e bem-estar do próximo), com uma amostra brasileira $(N=$ 335). Além de apresentar as instruções necessárias à aplicação da Escala de Altruísmo, os autores oferecem normas para a interpretação dos escores gerados para os três fatores dessa escala.

Resiliencia é como se chama o capítulo nono, escrito por Caroline Tozzi Reppold, Janaína Thais Barbosa Pacheco e Léia Gonçalves Gurgel. Além de discutir questões que envolvem a definição da resiliência e a situação atual da pesquisa sobre o construto, com ressalva a controvérsias que envolvem a avaliação desse construto, as autoras apresentam seis instrumentos internacionais para avaliação da resiliência. Outrossim, apesar das diferentes medidas internacionais, os autores atentam que a avaliação desse construto é controversa e merece cuidado por parte dos profissionais e pesquisadores.

O último capítulo foi escrito por Luciana Karine de Souza, Juliana Ávila-Souza e Gustavo Gauer e intitula-se Escala de Autocompaixão. Nesse capítulo, os autores apresentam a Escala de autocompaixão, composta por 26 itens que avaliam quatro componentes do construto (mindfulness, bondade consigo, senso de humanidade e autocrítica). Essa escala foi validada com amostras brasileiras recentemente (Souza \& Hutz, 2016), cujo estudo de adaptação está reportado nesse livro, juntamente com normas para a interpretação dos escores obtidos com a escala, separados por sexo.

Tendo o livro Avaliação em Psicologia Positiva: Técnicas e Medidas sido apresentado, faz-se válido ressaltar que esse livro, além de ser uma representação do avanço na produção nacional em Psicologia Positiva, aponta a ímpar contribuição que o Laboratório de Mensuração da UFRGS, liderado pelo professor Cláudio Simon Hutz, tem feito à ciência psicológica nacionalmente. Por oferecer diferentes medidas de avaliação, o livro configura-se como um valioso instrumento de consulta para psicólogos que utilizam a Psicologia Positiva tanto em pesquisas quanto em intervenções. Igualmente, as tabelas normativas, oferecidas ao longo do livro, contribuem para que os psicólogos atuantes possam fazer uso desses instrumentos de forma adequada, característica que afetará a qualidade das avaliações efetuadas por esses profissionais.

\section{Referências}

Souza, L., K. de, \& Hutz, C., S. (2007). A qualidade da amizade: adaptação e validação dos questionários McGill. Aletheia, 25, 82-96.

Souza, L., K. de, \& Hutz, C., S. (2016). Adaptation of the Self- Compassion Scale for use in Brazil: Evidences of Construct Validity. Trends in Psychology, 24. 159-172.

Recebido 30/06/2016

Reformulação 08/08/2016

Aceito 30/09/2016 
Sobre o autor:

Jeferson Pires é mestre em Psicologia pelo Programa de pós-graduação em Psicologia da Universidade Federal de Santa Catarina, na Linha de Avaliação em Saúde e Desenvolvimento e doutorando em Psicologia no mesmo programa. Possui interesse em fenômenos da Psicologia Positiva, além de integrar o Laboratório de Avaliação Psicológica (LPAP), na UFSC.

Contato com o autor:

Campus Reitor João David Ferreira Lima - Trindade

Bloco C. Térreo. Sala 3B ou Cx. Postal: 476

CEP: 88040-900

Florianópolis-SC, Brasil

E-mail: jefersongp@gmail.com

Psico-USF, Bragança Paulista, v. 21, n. 3, p. 687-689, set./ deæ. 2016 